Artigo Original

\title{
Alcoolismo: impactos na vida familiar
}

\section{Ketlen Patrycia Alves Cordeiro}

(D) https://orcid.org/0000-0002-2229-3495

Lavinia Luzia Gomes Souza ${ }^{1}$

(ID) https://orcid.org/0000-0003-4779-0591

Raquel Schwenck de Mello Vianna Soares²

(D) https://orcid.org/0000-0003-2298-6109

Ludmila Cotrim Fagundes 3,4

(D) https://orcid.org/0000-0001-5841-8280

Wellington Danilo Soares ${ }^{1,5}$

(DiD https://orcid.org/0000-0001-8952-9717

${ }^{1}$ Faculdade de Saúde e Humanidades Ibituruna, Curso de Psicologia, Montes Claros, MG, Brasil.

${ }^{2}$ Universidade Federal dos Vales do Jequitinhonha e Mucuri, Faculdade de Humanidades, Diamantina, MG, Brasil.

${ }^{3}$ Universidade Estadual de Montes Claros, Curso de Medicina, Montes Claros, MG, Brasil.

${ }^{4}$ Bolsista do Programa Institucional de Bolsas de Iniciação Científica, Universidade Estadual de Montes Claros, Montes Claros, MG, Brasil.

${ }^{5}$ Universidade Estadual de Montes Claros, Departamento de Educação Física, Montes Claros, MG, Brasil.
Objetivo: identificar os problemas acarretados pelo consumo excessivo do álcool, bem como as consequências que ele traz à família. Método: o instrumento utilizado foi uma entrevista semiestruturada, com roteiro composto por 12 questões elaboradas pelos próprios pesquisadores, para responder às temáticas propostas. Para a análise das entrevistas, utilizouse a Análise do Conteúdo e, como ferramenta de análise, empregou-se o software NVivo11, destinado ao tratamento de dados em investigação qualitativa. Resultados: durante o tratamento das entrevistas, elaboraram-se uma árvore categorial, que apresenta o álcool como núcleo, e quatro nós categoriais como aspectos principais da entrevista, sendo eles: início do uso; consequências para a família; problemas pelo consumo excessivo e ajuda. Conclusão: podem-se depreender as consequências negativas que o uso excessivo do álcool gera para as relações familiares, sendo este o eixo da vida de um alcoolista mais devastado. Além disso, é importante salientar que o mesmo eixo familiar destruído é base para a retomada de uma mudança como respaldo para a procura de auxílio de entidades competentes, como os Alcóolicos Anônimos.

Descritores: Alcoolismo; Família; Comportamento de Ajuda; Alcoólicos Anônimos.

\section{Como citar este artigo}

Cordeiro KPA, Souza LLG, Soares RSMV, Fagundes LC, Soares WD. Alcoholism: impacts on family life. SMAD, Rev Eletrônica Saúde Mental Álcool Drog. 2021 jan.- mar.;17(1):84-91. doi: https://dx.doi.org/10.11606/issn.1806-6976.smad.2021.168374 


\section{Alcoholism: impacts on family life}

Objective: identify the problems caused by excessive alcohol consumption, as well as the consequences it brings to the family. Method: the instrument used was a semi-structured interview, with a script composed of 12 questions prepared by the researchers themselves, to answer the proposed themes. For the analysis of the interviews, Content Analysis was used and, as an analysis tool, the NVivo11 software was used, aimed at processing data in qualitative research.

Results: during the treatment of the interviews, a categorical tree was elaborated, which presents alcohol as the nucleus, and four categorical knots as main aspects of the interview, being them: beginning of the use; consequences for the family; problems by excessive consumption and help. Conclusion: the negative consequences that the excessive use of alcohol generates for family relationships can be inferred, and this is the axis of the life of a more devastated alcoholic. In addition, it is important to point out that the same destroyed family axis is the basis for the resumption of a change as a support for the search for help from competent entities, such as the Alcoholics Anonymous.

Descriptors: Alcoholism; Family; Helping Behavior; Alcoholics Anonymous.

\section{Alcoholismo: impactos en la vida familiar}

Objetivo: conocer la realidad del alcohólico e identificar los problemas causados por el consumo excesivo de alcohol, así como las consecuencias que trae a la familia. Método: el instrumento utilizado fue una entrevista semiestructurada con un guión compuesto por 12 preguntas, preparadas por los propios investigadores, para responder a los temas propuestos. Para el análisis de las entrevistas, se utilizó el Análisis de contenido y, como herramienta de análisis, el software NVivo11 para el procesamiento de datos en la investigación cualitativa. Resultados: durante el tratamiento de las entrevistas fue posible elaborar un árbol categórico que presenta el alcohol como núcleo y cuatro nodos categóricos como los aspectos principales de la entrevista, a saber: comienzo del uso; consecuencias para la familia; problemas de consumo excesivo y ayuda. Conclusión: uno puede entender las consecuencias negativas que el uso excesivo de alcoholico genera para las relaciones familiares, siendo este eje de la vida de un alcohólico el más devastado. Además, es importante tener en cuenta que el mismo eje familiar destruido es la base para la reanudación de un cambio, como apoyo para la búsqueda de ayuda de entidades competentes, como Alcohólicos Anónimos ( $A A)$.

Descriptores: Alcoholismo; Familia; Conducta de Ayuda; Alcohólicos Anónimos. 


\section{Introdução}

O uso de bebidas alcoólicas está atrelado à cultura em que, desde os primórdios, se fazia uso da mesma como gesto de comemoração em diversas festividades, atos religiosos, comerciais ou complementos culinários ${ }^{(1)}$. Contudo, o uso inapropriado/excessivo destas acarreta complicações para a vida do indivíduo. O alcoolismo tem aumentado progressivamente em toda sociedade, tornando-se um grande problema de saúde pública, e seu uso constante está ligado aos fatores de fácil acesso e baixo custo(2).

Considerada uma droga lícita, o álcool é um dos principais responsáveis pelas causas de óbitos por abuso de drogas no Brasil. De oito mil mortes por ano, o álcool é responsável por $85 \%$ delas. O número de dependentes cresce substancialmente, afetando tanto jovens quanto adultos. Ainda que seja ingerido em poucas quantidades, acarreta consequências graves para todos ao redor do alcoolista. Os malefícios provocados pelo alcoolismo vão além, pois pessoas que possuem essa dependência têm maiores chances de sofrer algum tipo interferência no ambiente de trabalho, ou seja, é prejudicial tanto para as relações familiares quanto para as relações do meio social e profissional(3).

O indivíduo dependente do álcool raramente irá admitir e compreender que está passando por um processo de enfermidade, pois ele acredita que poderá parar a qualquer momento que desejar. Esse fator impede que grande parte das pessoas etilistas busque tratamento necessário para ajudá-la, o que começa a acarretar fatores negativos para a mesma e para suas relações mais próximas. A realidade da família que convive com o alcoolismo é de preocupações e conflitos, o que desgasta as relações afetivas no convívio familiar $(2,4)$.

Após a instalação da dependência, o tratamento é de crucial importância para que o indivíduo alcoolista consiga sua reinserção no meio social após os danos causados pelo vício. A literatura científica evidencia dados importantes sobre o uso e tratamento de alcoolistas, como, por exemplo, o fato de que $11,2 \%$ da população brasileira faz parte do grupo de dependentes(5).

Por meio deste tratamento, será possível que o alcoolista volte para suas relações familiares, sociais e a ter acesso a atividades profissionais, ou seja, ele começaria a retornar à sua vida com as atividades que fossem interrompidas. Para ajudar nessa reinserção, dar apoio e acolhimento aos alcoolistas, existem o grupo dos Alcoólicos Anônimos (AA) e outros grupos que fazem trabalhos de auxílio ao alcoolista e consumidores de outras drogas oferecidos de maneira gratuita pelo poder público(5).

O grupo dos AA baseia-se em uma comunidade onde participam pessoas de ambos os sexos, compartilham entre si suas perdas, dificuldades, consequências, forças e determinantes que os auxiliam na resolução e recuperação frente ao alcoolismo. Isto ocorre como forma de ajudarem os outros participantes em um bem comum: vencer 0 vício. O que se pede para que os participantes que entrem no grupo é a força de vontade em parar o consumo do álcool. Ser membro do AA não exige nenhum custo, pois a rede de apoio não é internamente ligada a nenhum tipo de instituição ou questões religiosas. A questão crucial é ajudar uns aos outros no controle do vício para que se mantenham sóbrios ${ }^{(6)}$.

A partir do exposto, este trabalho teve como objetivo geral identificar os problemas acarretados pelo consumo excessivo do álcool, bem como as consequências que ele traz, principalmente, para a família.

Esta temática urge da necessidade de aprofundar as discussões sobre as influências decorrentes do alcoolismo no meio familiar, das dificuldades frente ao vício e a importância da busca por ajuda como forma de enfrentamento. Nesse contexto, a maior produção de estudos e conteúdos sobre quais são os impactos causados no âmbito familiar, decorrentes do consumo excessivo do álcool por um de seus integrantes, pode ser o início de um processo de transformação que começa na academia e estende seus reflexos para a realidade social.

\section{Método}

Trata-se de uma pesquisa descritiva, com abordagem qualitativa e corte transversal. O estudo contou com uma amostra de nove homens, com faixa etária de 30 a 69 anos ( $x=47,1$ anos), selecionados aleatoriamente, pertencentes do grupo de AA da cidade de Montes Claros - MG. Foram incluídos homens com idade superior a 17 anos e que tivessem um histórico de consumo abusivo de álcool e excluídos aqueles que não aceitassem participar de forma voluntária da pesquisa e/ou não comparecessem para entrevista após três tentativas.

Os participantes da pesquisa são tratados, ao longo do trabalho, como entrevistados, sendo caracterizados como E1, E2, E3, E4, E5, E6, E7, E8 e E9.

$O$ instrumento utilizado foi uma entrevista semiestruturada com roteiro composto por 12 questões, elaboradas pelos próprios pesquisadores, para responder às temáticas propostas.

Para a coleta de dados, inicialmente, foi feito contato com a direção do AA no intuito de conseguir a autorização para a realização da pesquisa. Neste momento, foi apresentada a proposta do estudo. Após a autorização, foi realizada uma reunião com os participantes do grupo para explanar os objetivos, justificativa e metodologia do estudo. Aqueles que aceitaram participar de forma voluntária assinaram o Termo de Consentimento Livre e Esclarecido (TCLE) contendo todas as informações pertinentes à pesquisa. 
Todas as entrevistas foram realizadas em uma sala reservada na instituição pesquisada e ocorreram no mês de setembro/2019, sendo realizadas pelos próprios pesquisadores.

Para a análise das entrevistas, utilizou-se a Análise de Conteúdo e, como ferramenta de análise, empregou-se o software NVivo11, destinado ao tratamento de dados em investigação qualitativa. A utilização de programas informáticos de Análise de Conteúdo possibilita um tratamento mais completo e viável. Comparativamente à análise de conteúdo "à mão", estes programas oferecem uma inovação extremamente importante: a possibilidade de testar e relacionar hipóteses, valendo-se dos recursos e benefícios trazidos pela informática(7-8).

Facilitaram-se, recorrendo aos recursos informáticos, as rotinas de análise de dados qualitativos. Como tal, neste estudo, procedeu-se: à organização dos documentos; à formatação dos documentos para uniformização; ao tratamento das entrevistas pelos contextos de aplicação; à análise das variáveis do estudo, problema e enquadramentos ${ }^{(9)}$.

Para fins de esclarecimentos das denominações utilizadas ao longo da pesquisa em decorrência do software NVivo, explicitam-se algumas nomenclaturas: a) codificação é o processo de agrupar itens semelhantes, ou seja, o processo de agrupar as falas dos entrevistados em temas semelhantes; b) referência é a quantidade de vezes em que determinada categoria foi citada na fala dos entrevistados; c) categorias são compostas por um termo chave que indica a significação central do conceito que se quer apreender e de outros indicadores que descrevem o campo semântico do conceito; d) árvore categorial é o esquema gráfico em que as categorias relativas à interpretação dos dados são dispostas por meio de uma imagem sequencial e objetiva; e) ramo da árvore categorial é a junção das categorias e subcategorias de um mesmo tronco da árvore categorial(10).

Este estudo foi submetido e aprovado pelo Comitê de Ética em Pesquisa (CEP) das Faculdades Unidas do Norte de Minas - Funorte sob o Parecer no 3.361.169/2019.

\section{Resultados}

Durante o tratamento das entrevistas, com o auxílio do software Nvivo11, foi possível construir uma árvore categorial que apresenta o álcool como núcleo e quatro nós categoriais como aspectos principais das entrevistas, sendo eles: início do uso; consequências para a família; problemas pelo consumo excessivo e ajuda. Essas categorias não foram elaboradas previamente, mas identificadas na própria análise das falas dos entrevistados.

Os resultados estão explicitados de acordo com a Figura 1, que representa a árvore categorial final.

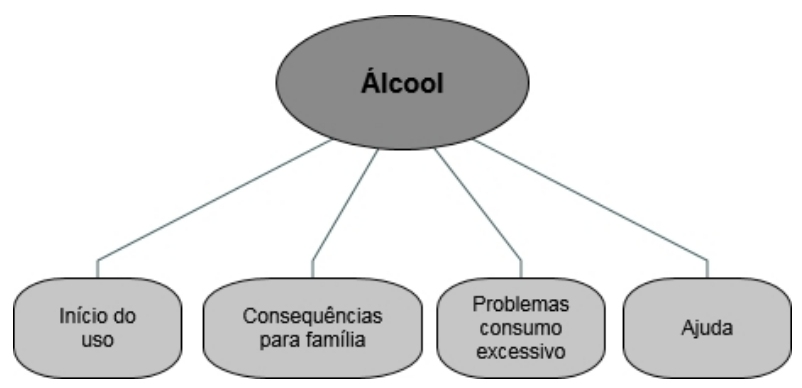

Figura 1 - Árvore categorial final

É possível perceber, com a Figura 1, que o álcool é centro da vida do etilista, sendo ainda o gerador de consequências, muitas vezes, fatídicas para todos ao seu redor. Logo abaixo e como primeira categoria apresentada, pode-se apontar o "início do uso" do álcool, ou seja, o que motivou aquele usuário a começar a consumir o álcool, podendo ser em qualquer idade.

Logo após, foi possível diagnosticar, a partir das falas dos entrevistados, que este uso gerava consequências no ambiente familiar, sendo categorizado como "consequências para a família", isto é, como a família reagia diante da situação de ter um ente alcoolista.

Em maior profundidade, e antes de conseguirem procurar auxílio, diagnosticaram-se alguns "problemas no consumo excessivo", o que a bebida alcóolica gerava na vida do usuário, quer dizer, não somente no âmbito familiar, mas em todos os aspectos (social, laboral e sentimental).

Por fim, foi possível perceber, nas falas dos entrevistados, que há um momento limite em suas vidas, em que há a necessidade de procurar auxílio, sendo este nó categorizado como "ajuda". Nesta categoria, foi possível perceber como a família auxilia nesta busca por resgate da própria pessoa, além de trazer benefícios para todos.

Com relação ao início do uso, as falas dos entrevistados referentes a cada categoria puderam ser demonstradas por meio de gráficos, apresentando a quantidade de referências feitas por cada entrevistado a cada um dos nós, como demonstrado abaixo na Figura 2 do primeiro nó (início do uso).

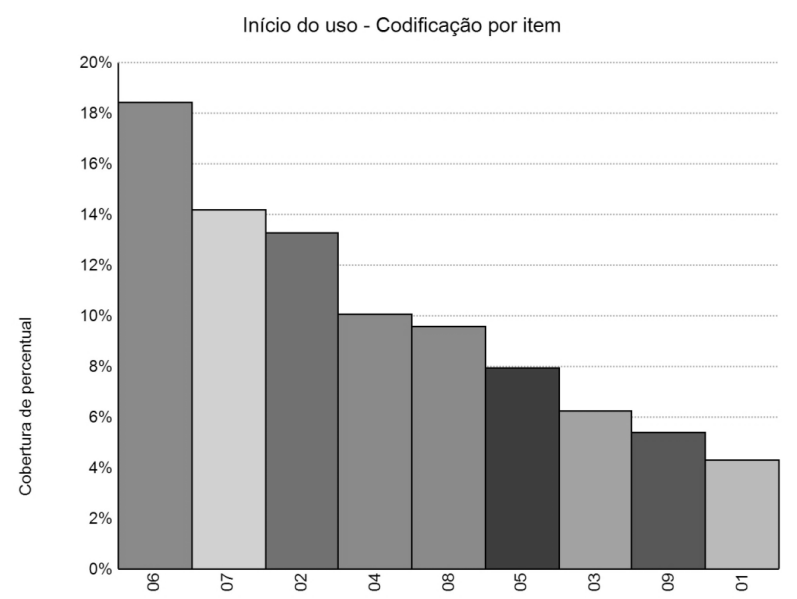

Figura 2 - Primeiro nó categorizado (início do uso) 
A primeira das quatro categorias (nós) diagnosticadas a partir das falas dos entrevistados foi o "início do uso", sendo esta uma categoria importante, uma vez que trata como tudo começou na vida do etilista, podendo ser vista como uma lacuna a ser estudada por outros pesquisadores com o intuito de cercear o início do uso do álcool.

Como se pode perceber, no primeiro nó (categoria), demonstrado na Figura 2, o entrevistado que mais mencionou o início do uso do álcool em sua vida foi o E6, com mais de $18 \%$ das referências. Já o entrevistado que menos mencionou esta categoria foi o $\mathrm{E} 1$, com $4 \%$ das referências.

Diante de todos os entrevistados, o que mais se destacou foi o participante de número seis, considerando que foi o que explicou, de maneira mais clara, as questões do seu início com o álcool.

Comecei quando eu era bem novo, acho que desde uns 19 anos mais ou menos; sempre bebi de tudo um pouco, mas de forma controlada, só quando tinha alguma festa, alguma coisa assim. Fiquei um tempo bom bebendo assim, mais fui ficando mais velho, as preocupações foram tomando conta da cabeça, sabe, aí, comecei a aumentar a quantidade, conheci alguns amigos que jogavam sinuca, aí, comecei a ir jogar com eles. Jogávamos três vezes por semana depois do trabalho, e todos os dias tinha bebedeira, fui me acostumando e, quando percebi, já estava bebendo de maneira incontrolada. (E6)

O segundo nó (categoria) apresentado é "consequências para a família", sendo caracterizado como um item central para a análise, pois vem tratar de como a utilização do álcool gera, em sua maioria, malefícios para os entes mais próximos.

Podem-se perceber as referências a este nó de acordo com a Figura 3.

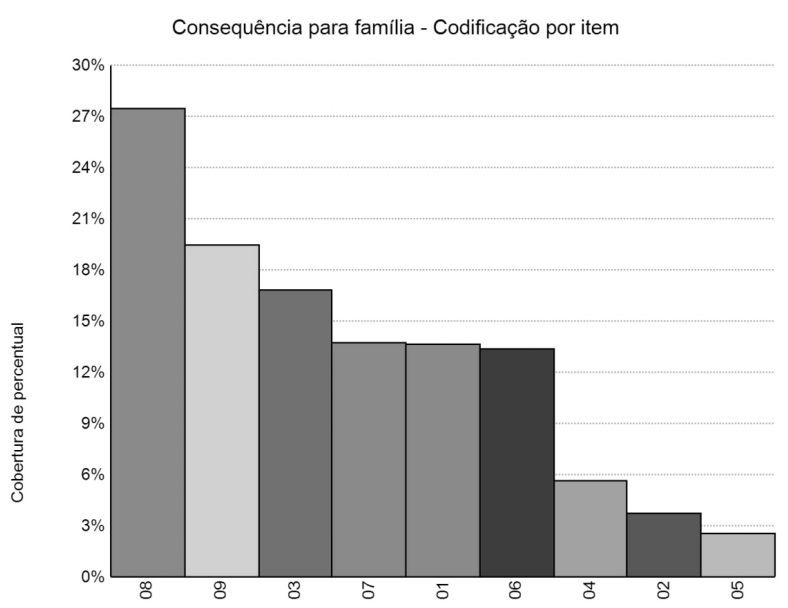

Figura 3 - Segundo nó categorizado (consequência para a família)

A Figura 3 traz que o entrevistado que mais citou esta categoria foi o E8, fazendo referência a este nó em mais de
$27 \%$. Uma de suas falas, que caracteriza e demonstra esta consequência, pode ser observada a seguir.

Minha esposa e meus filhos sofriam muito quando eu chegava em casa bêbado. Às vezes, chegava caindo, minha esposa tinha que me ajudar a ir para o quarto, meus filhos ficavam me olhando estranho. Teve uma vez que eu dei um tapa na minha esposa porque ela não estava conseguindo me levantar, me arrependo muito disso. No outro dia, eu acordava morrendo de vergonha, mais nem isso fazia com que eu parasse com a bebida (cabeça baixa). (E8)

Minha esposa me largou por três anos porque não aguentava mais a situação que estava dentro de casa, meus filhos também se afastou de mim, acho que eles tinham vergonha (cabeça baixa, voz trêmula ao falar que achava que os filhos tinham vergonha dele). (E8)

Em contrapartida, o entrevistado que menos fez menção a esta categoria foi o E5, com menos de $3 \%$ das referências a esta categoria, trazendo, em seu discurso, somente que os familiares sofreram muito com esta situação, demonstrada na fala a seguir.

Já fiz a minha família sofrer muito. Porque pai, mãe, irmãos. Depois, vinha o resto da família, mãe, irmãos, parentes, amigos, todos sofriam comigo. (E5)

A partir do momento em que o sujeito estabelece relações de sentido com o mundo de acordo com a elaboração de suas vivências, este começa a emitir um juízo pessoal e aprende o significado daquilo que teve como experiência(11).

O penúltimo nó categorizado foi relacionado aos problemas, consequências com o consumo excessivo do álcool, sendo demonstrado na Figura 4.

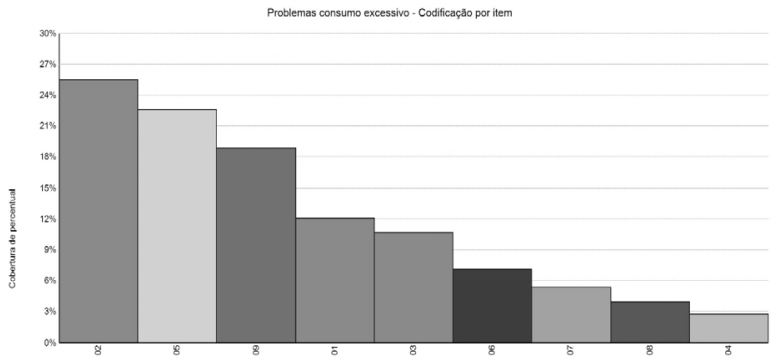

Figura 4 - Terceiro nó categorizado (Problemas com consumo excessivo)

De acordo com a Figura 4, em meio a todas as entrevistas e citações sobre o consumo em excesso do álcool, o entrevistado dois (E2) foi o que teve mais frequência em suas falas, com mais de $24 \%$. Pôde-se observar um pouco esse fato diante da seguinte fala.

A bebida "desgraçou" a minha vida. Afastei da família, amigos, perdi emprego. Eu trabalhava de servente, as pessoas foram perdendo a confiança em mim. (E2). 
Ficar diante da realidade, poder repensar as atitudes de beber incontrolavelmente e analisá-las de acordo com as consequências advindas do alcoolismo, como a perda da família, a perda de amigos, a perda de emprego, onde "desgraçou", abrangem, inclusive, a perda do próprio sentido da vida.

Em contrapartida, o entrevistado que menos teve referências em sua fala, com relação a este terceiro nó, foi o E4, tendo somente duas referências, correspondendo a menos de $3 \%$, conforme demonstrado a seguir.

Eu perdi até namorada porque bebia. Já passei mal demais com ressaca. (E4)

O último nó categorizado, e talvez o que mais surte efeito positivo na vida dos etilistas e seus entes, é a "ajuda", a procura de auxílio de outrem na tentativa de se livrar deste vício. Para tanto, serão apresentados os dados deste nó na Figura 5.

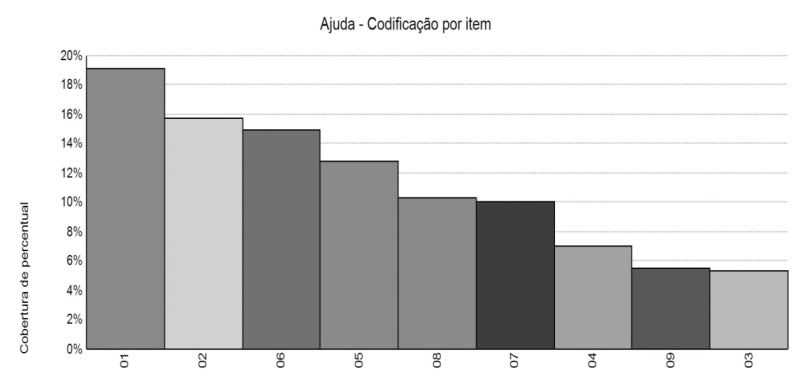

Figura 5 - Quarto nó categorizado (Ajuda)

Com relação ao quesito ajuda, foi observada uma frequência maior de citação (mais de 18\%) no entrevistado de número um (E1). Nos depoimentos a seguir, é possível identificar claramente isso.

Quando o vício ficou insustentável, quando eu vi que, sozinha, eu não dava conta mais, via meus filhos sofrer e aquilo me doía demais. Aí, eu vi que tinha que mudar de vida, que, daquele jeito, não dava pra ficar. Se eu quisesse "livrar" do vício, tinha mais gente querendo me ajudar. Não foi fácil parar de beber, nenhum vício é fácil de acabar com ele, mas, graças a Deus, eu consegui. (E1)

Ao relatar suas vivências, suas perdas, a fragilidade em não conseguir sozinho se livrar do vício perante o álcool, o entrevistado identifica, em si, uma vontade de mudar de vida, de poder extrair, do sofrimento, uma reviravolta, uma chance de ser melhor, uma oportunidade de transformar a si próprio.

Com relação ao entrevistado que menos se posicionou sobre esta categoria, o E3 destacou-se, com menos de 6\% das citações referentes a este nó, representando apenas uma fala, como demonstrado abaixo.

Em qual momento você procurou ajuda? Por quê? Como foi recebido? Quando eu acabei com tudo, né, já que eu fiquei sozinho, tinha que tentar cuidar de mim. (E3)

\section{Discussão}

Este estudo propôs analisar os impactos na vida familiar de pessoas alcoolistas. A partir das falas dos entrevistados, ficaram evidenciadas as consequências geradas ao longo dos anos por parte tanto dos familiares, amigos, bem como para o próprio alcoolista.

No que diz respeito ao início do consumo do álcool, estudos apontaram que as pessoas alcoolistas tiveram o hábito de dar início ao consumo do álcool em idades precoces, advindo do convívio com pessoas que ingeriam o álcool. Esposas ainda relataram ter experienciado também a ingestão do álcool devido ao ver e conviver com seus maridos que faziam o uso de bebidas ${ }^{(12)}$. Tal estudo é respaldado por esta pesquisa, uma vez que dois participantes (E5 e E1) também relataram ter ingerido álcool precocemente, mais precisamente aos dezesseis anos de idade (E5) e por convivência com o cônjuge (E1).

Pôde-se analisar a importância do papel da família no processo de entender o quesito consumo em excesso, fazendo-se uma ponte entre o alcoolista e a busca por ajuda. E, ainda que a família apoie o etilista, este tem plena consciência que brigas, rompimentos de vínculos, perda da confiança e da credibilidade advêm do álcool. Em contrapartida, há famílias que, ao perceberem o abuso de álcool, entendem como um fator de interação social e passam a negar que os problemas enfrentados tenham ligação com o uso/abuso deste, buscando, dessa maneira, justificativa para os conflitos existentes no $\operatorname{lar}^{(13)}$.

Para alguns estudiosos, o indivíduo consegue ver que, no início, ele permanece cercado pela família e pelos amigos, entretanto, a partir do momento em que a doença se instala e progride, essas mesmas pessoas, que estavam ao seu lado, começam a se afastar ${ }^{(14)}$. Em algumas situações, a família isola-se do doente por medo da agressividade e da violência momentâneas geradas pela bebida.

Eu ciumava muito da minha mulher; quando bebia, me transformava, acusava ela, xingava ela, foi aí que tudo foi virando um inferno. (E3)

Apresentaram-se, considerando o fato de que o álcool é um dos principais influenciadores de problemas familiares e sociais na atualidade ${ }^{(4)}$, resultados semelhantes aos deste estudo. Essa semelhança dá-se referente a fatores de afastamento dos filhos e rompimento de laços matrimoniais, o que acontece quando as consequências do alcoolismo já estão se tornando um caso crítico.

Ao se tratar das consequências para as famílias, as perdas vividas pelo alcoolista podem incluir até o rompimento matrimonial. Porém, ainda que a família aja como grande motivadora, para impulsionar o sujeito na busca de tratamento, tanto quando se busca na literatura 
quanto os dados coletados apontam que o desejo pela mudança depende, principalmente, de fatores intrínsecos a cada indivíduo(3).

Graças ao meu poder superior (Deus), que me resgatou daquela vida, aqui estou e posso ajudar a qualquer outro alcoólatra a recuperar, basta ele querer e admitir que ele é impotente perante ao álcool, aí, tudo dá certo. (E5)

Sobre a forma como o alcoolismo afeta as relações familiares e sociais, pode-se observar que, quando o sujeito entra no mundo do consumo excessivo do álcool, ele prejudica o exercício da sua responsabilidade como esposo, pai, trabalhador. O abandono das responsabilidades diante das áreas social e familiar é o primeiro passo para o desemprego e para a solidão afetiva(15). A partir desse ponto de vista, é possível interligar esses aspectos a vários quesitos citados nas entrevistas em que alguns participantes relatam ter perdido a confiança dos filhos e da esposa e relatam também ter perdido oportunidades de emprego. Quando chegam a esse ponto, considera-se que o vício já está em um grau bem avançado em que o usuário não tem mais controle sobre a quantidade que consome.

Quando se trata de ajuda, o grupo dos AA faz-se muito presente, como sendo uma das principais formas na busca por tratamento. Busca-se a tentativa de construir uma relação que ajude a fortalecer a confiança na pessoa por meio da oferta de cuidado e atenção sem que esta seja julgada, possibilitando a escuta ao compartilhar os problemas vivenciados ${ }^{(16)}$. Faz-se uma analogia a partir das falas dos entrevistados. Para o E5, por exemplo, estar no AA é estar com os amigos de verdade, é uma família que se conquista na busca de um bem comum: ajudarem-se.

Foi notório que, no $A A$, ninguém é induzido a possuir certa religião, nem se confessar crente a um determinado Deus, mas a maioria dos entrevistados demonstrou a crença em um poder superior a eles, que os auxilia a não recair. Entretanto, cada membro vivencia sua experiência espiritual de maneira individualizada e em conformidade com a concepção que cada um possui de Deus(11).

O grupo de AA tem me ajudado, colaborado demais com a minha recuperação; eu só tenho que agradecer ao meu poder superior que, na minha concepção, é Deus e, segundamente, os companheiros que me abraçaram de verdade. (E5)

Contudo, ainda que se entendam a necessidade de falar sobre o álcool e as consequências acarretadas para a saúde do indivíduo, compreendendo-o em um contexto biopsicossocial, suas relações familiares, ciclos de amizade e empregatícias, é válido falar sobre a relevância de que se realizem mais pesquisas voltadas a esta temática sobre a qual muitas pessoas ainda possuem preconceito e até mesmo vergonha em falar e aceitar-se alcoolista. Importante ressaltar que, ainda que se tenha muita adesão por parte dos participantes em abrirem suas realidades para as pesquisadoras, alguns ainda se sentem tímidos ao falar sobre o assunto, desde questões como vir de uma cidade pequena, onde se é julgado a todo instante por suas condutas, ou até mesmo por se sentirem menosprezados, sem valor pela sua condição.

O estudo apresenta a limitação inerente a uma pesquisa com desenho transversal pela impossibilidade da relação causa-efeito.

\section{Conclusão}

$\mathrm{O}$ alcoolismo tem surgido como um grande agravante de conflitos na dinâmica familiar. Este estudo possibilitou identificar que o impacto do alcoolismo é um dos principais problemas enfrentados pela família e sociedade atualmente, bem como o aumento do número de usuários da substância etílica. O rompimento de laços afetivos motivado por brigas, afastamento de seus membros e até mesmo rompimento matrimonial, constatando-se ainda as perdas físicas, materiais e morais são alguns dos vários problemas acarretados pelo consumo exacerbado do álcool.

A partir das falas dos participantes, sendo essas voltadas para as influências do alcoolismo no meio familiar, foi possível constatar que tanto o alcoolista quanto a família sofrem diante da situação de dependência do álcool. O processo de reconhecimento do vício dá-se como o mais difícil na busca por ajuda e enfrentamento. Após esse processo de reconhecimento, o grupo AA mostrou-se bastante efetivo no processo de recuperação. Entende-se, ainda, que este passe a ser a rede de apoio do etilista, onde ele se identifica com outros usuários e, muitas vezes, se torna uma nova rede de amizades. Este fato faz com que o indivíduo tente se recuperar do vício, melhorar o relacionamento intrafamiliar e retomar às suas atividades cotidianas.

Em vista dos argumentos apresentados, este artigo demonstra sua relevância, pois contribui, por meio das vivências pessoais de cada participante, para um maior conhecimento sobre os impactos na vida familiar do alcoolista e a influência que o grupo dos AA possui para a motivação no processo de reabilitação.

\section{Referências}

1. Lopes APAT, Ganassin GS, Marcon SS, Decesaro MDN. Alcohol abuse and its relationship in the family context. Est Psicol. 2015;20(1):22-30. doi: 10.5935/1678-4669.20150004

2. Ferraboli CR, Guimarães AN, Kolhs M, Galli KSB, Guimarães AN, Schneider JF. Alcoholism and family dynamics: feelings shown. Cienc Cuidado Saúde. 2015;14(4):1555-63. doi: 10.4025/cienccuidsaude. v14i4. 27245 
3. Antunes F, Oliveira MLF. Family relations and alcohol usage:an integrative review. Rev Uningá Review. [Internet]. 2015;21(3)27-32. [cited Aug 10 2019]. Available from: <http://revista.uninga.br/index.php/ uningareviews/article/view/1623/1234>.

4. Vilela JS, Loreto MDS, Vilela JM, Silva AO. Influence of alcoholism in dependents family life projects. Oikos: Rev Bras Econ Doméstica. [Internet]. 2015;26(1):18-45. [cited Aug 10 2019]. Available from: <https://periodicos. ufv.br/oikos/article/view/3695/1963>.

5. Carvalho JES, Liotti DBM, Lenzi MCR. The Alcohol and Drugs Psychossocial Care Centers and Alcoholics Anonymous: the treatment process from the point of view of users. Cad Bras Saúde Mental. [Internet]. 2015;7(16):41-61. [cited Aug 10 2019]. Available from: <https://periodicos.ufsc.br/index.php/cbsm/article/ view/68750/41379>.

6. Reis S, Silva AC, Castro FV. Alcoholics Anonymous. Rev Psicol. 2016;2(1):375-84. doi: 10.17060/ijodaep. 2016. n1.v2.179

7. Aranha A, Gonçalves F. Content analysis methods: nud $*$ ist (non-numerical unstructed data indexing, searching and theorizing) - nvivo7. Vila Real: UTAD; 2007. 27 p.

8. Bardin L. Content Analysis: Leurence Bardin's vision. Rev Eletrôn Educ. 2011;6(1):383-7. doi: $10.14244 / 19827199$

9. Miles M, Huberman M. Qualitative data analysis: An expanded Sourcebook. Thousand Oaks: Sage; 1994. 336 p.

10. Strauss A, Corbin J. Basics of qualitative research grounded theory procedures and techniques. London: Sage Publications; 1990. $21 \mathrm{p}$.

11. Nogueira DMM, Coelho AG. Alcoholics anonymous and relapse: analysis in the light of the elemental experience. Psicol Rev. 2018;24(2):541-58. doi: 10.5752/P.1678-9563.2018v24n2p541-558

12. Rodríguez JSL, Martín DG, Sánchez ID, Serrano ML. Alcoholic patients' response to their disease: perspective of patients and family. Rev. Latino-Am. Enfermagem. 2015;23(6):1165-72. doi: 10.1590/0104-1169.0516.2662 13. Cyrino LAR, Araujo BB, Santos CC, Bapstista LV. Familial co-dependence of alcohol abusing people. Rev Cesumar Ciências Humanas e Sociais Aplicadas. [Internet]. 2016;21(2):457-70. [cited Aug 10 2019]. Available from: <https://periodicos.unicesumar.edu.br/ index.php/revcesumar/article/download/3563/2905/>.

14. Soares JR, Farias SNP, Donato M, Mauro MYC, Araujo EFS, Ghelman, LG. Relevance of family role in the prevention of alcoholism relapse. Rev Enferm. UERJ.
[Internet]. 2014;22(3):341-6. [cited Aug 10 2019]. Available from: <http://www.facenf.uerj.br/v22n3/ v22n3a08.pdf>.

15. Matos JC, Monteiro CFS. Cohabitation versus alcoholism: analyzingthe daily life of the relatives. Rev Eletrôn Gestão Saúde. [Internet]. 2015;6(2):1623-37. [cited Aug 10 2019]. Available from: <periodicos.unb. br/index.php/rgs/article/view/2970>.

16. Barbosa SM, Silva MR, Melchisedech CS. Group of Alcoholic Anonymous: motivation of participants in the treatment process. Psicologia.pt. [Internet]. 2018;1:117. [cited Aug 10 2019]. Available from: <https://www. psicologia.pt/artigos/textos/A1167.pdf>.

\section{Contribuição dos autores}

Concepção e planejamento do estudo: Ketlen Patrycia Alves Cordeiro e Lavinia Luzia Gomes Souza. Obtenção dos dados: Ketlen Patrycia Alves Cordeiro, Lavinia Luzia Gomes Souza e Ludmila Cotrim Fagundes. Análise e interpretação dos dados: Raquel Schwenck de Mello Vianna Soares. Redação do manuscrito: Ketlen Patrycia Alves Cordeiro, Lavinia Luzia Gomes Souza e Ludmila Cotrim Fagundes. Revisão crítica do manuscrito: Wellington Danilo Soares.

Todos os autores aprovaram a versão final do texto. Conflito de interesse: os autores declararam que não há conflito de interesse. 